\title{
The Adjusted Effect of Maternal Body Mass Index, Energy and Macronutrient Intakes during Pregnancy, and Gestational Weight Gain on Body Composition of Full-Term Neonates
}

\author{
Luis Pereira-da-Silva, MD, $\mathrm{PhD}^{1,2}$ Catarina Cabo, $\mathrm{RD}^{3}$ Ana Catarina Moreira, $\mathrm{RD}, \mathrm{MSC}^{3}$ \\ Daniel Virella, MD, MSc ${ }^{4}$ Tatiana Guerra, RD $^{3}$ Tania Camoes, RD $^{3}$ Ana Rita Silva, RD $^{3}$ \\ Rute Neves, $\mathrm{MD}^{2}$ Goncalo Cordeiro Ferreira, $\mathrm{MD}^{1,2}$
}

\footnotetext{
${ }^{1}$ Neonatal Division, Hospital Dona Estefânia, Centro Hospitalar de Lisboa Central, Lisbon, Portugal

2 Nutrition Lab, Hospital Dona Estefânia, Centro Hospitalar de Lisboa Central, Lisbon, Portugal

${ }^{3}$ Department of Dietetics and Nutrition, Lisbon School od Health

Technology

${ }^{4}$ Research Unit, Centro Hospitalar de Lisboa Central, Lisbon, Portugal
}
Address for correspondence Luis Pereira-da-Silva, MD, PhD, Hospital Dona Estefânia, Rua Jacinta Marto, 1169-045 Lisbon, Portugal (e-mail: I.pereira.silva@netcabo.pt).

Am J Perinatol

\begin{abstract}
\section{Keywords}

- air displacement plethysmography

- anthropometry

- body composition

- maternal nutritional status

- neonate

Objective To evaluate the effect of prepregnancy body mass index (BMI), energy and macronutrient intakes during pregnancy, and gestational weight gain (GWG) on the body composition of full-term appropriate-for-gestational age neonates.

Study Design This is a cross-sectional study of a systematically recruited convenience sample of mother-infant pairs. Food intake during pregnancy was assessed by food frequency questionnaire and its nutritional value by the Food Processor Plus (ESHA Research Inc, Salem, OR). Neonatal body composition was assessed both by anthropometry and air displacement plethysmography. Explanatory models for neonatal body composition were tested by multiple linear regression analysis.

Results A total of 100 mother-infant pairs were included. Prepregnancy overweight was positively associated with offspring weight, weight/length, BMI, and fat-free mass in the whole sample; in males, it was also positively associated with midarm circumference, ponderal index, and fat mass. Higher energy intake from carbohydrate was positively associated with midarm circumference and weight/length in the whole sample. Higher GWG was positively associated with weight, length, and midarm circumference in females.

Conclusion Positive adjusted associations were found between both prepregnancy $\mathrm{BMI}$ and energy intake from carbohydrate and offspring body size in the whole sample. Positive adjusted associations were also found between prepregnancy overweight and adiposity in males, and between GWG and body size in females.
\end{abstract}

received

September 19, 2013

accepted after revision

November 5, 2013
Copyright $\odot$ by Thieme Medical

Publishers, Inc., 333 Seventh Avenue,

New York, NY 10001, USA.

Tel: +1(212) 584-4662.
DOI http://dx.doi.org/ 10.1055/s-0033-1363502. ISSN 0735-1631. 


\section{Background}

Pregnancy is considered as a three-compartment model where mother, placenta, and fetus interact to ensure fetal growth. ${ }^{1}$ Prepregnancy body mass index (BMI) is generally considered to reflect the maternal nutritional status, closely related to the total body fat content. ${ }^{2}$ Although overweight women are much more likely to have gestational diabetes and glucose intolerance, obesity is independently associated with increased risk of bearing large-for-gestational age infants. ${ }^{3}$

The mother's diet is recognized as one of the major environmental factors influencing the development and body composition of the fetus, and the quality of nutrition seems to be more important than energy intake alone. ${ }^{1,4}$ The effect of energy and protein intake during pregnancy on fetal growth remains controversial because interventional studies have been unable to confirm many of the associations found in observational studies. ${ }^{5}$

Positive deviations from the energy requirement can result in excessive gestational weight gain (GWG), even in mothers with normal weight. ${ }^{6}$ This may result in increased birth weight and body fat of the offspring, an effect that is enhanced if the mother is obese. ${ }^{7}$

When assessed in the first postnatal days, the body composition is a good indicator of the intrauterine nutritional status. ${ }^{8}$ Most studies assessing the effect of maternal nutritional factors on neonatal body composition have relied on neonatal anthropometry. ${ }^{9-13}$ Anthropometry may reasonably assess body size (reflected by both body weight and length) at birth but has many limitations in neonates ${ }^{14,15}$; it may not be accurate enough to assess body composition, especially adiposity, even by using skinfolds and models derived from direct measurements. ${ }^{16}$

Only a few studies have used more accurate estimates of neonatal body composition through direct methods, such as air displacement plethysmography (ADP)..$^{7,17,18}$ ADP has been validated in neonates, and is particularly convenient for being noninvasive, relatively rapid to perform, and not affected by movements, thus not requiring sedation or immobilization. ${ }^{19}$

This study evaluates the concurrent effect of prepregnancy BMI, energy and macronutrient intakes during pregnancy, and GWG on the body composition of healthy full-term appropriate-for-gestational age (AGA) neonates.

\section{Methods}

A cross-sectional study was conducted in the maternity and the nutrition laboratory of a level III pediatric hospital. Ethical committee approval and parental-informed consent were obtained.

A convenience sample of mother-infant pairs was recruited systematically from April 2010 to June 2011. Two consecutive neonates scheduled for discharge on the days available for assessments at the nutrition laboratory were recruited. Sample size was limited by the restricted academic schedule of some of the researchers. The following are the criteria for inclusion: proper medical surveillance, singleton full-term neonate ( $\geq 37$ and $\leq 41$ weeks of gestation), and
AGA (birth weight $>3$ rd and $<97$ th percentiles for gestational age and gender $)^{20}$ neonates considered healthy. Neonates whose mothers had adverse conditions potentially affecting fetal nutrition and growth, such as type 2 diabetes mellitus, abnormal oral glucose tolerance test, inborn errors of metabolism, severe renal and cardiovascular disease, diastolic blood pressure during pregnancy $>90 \mathrm{~mm} \mathrm{Hg}$, or any reported consumption of alcohol, tobacco, or illicit drugs were excluded. $^{21}$

Maternal diet was assessed by a semiquantitative 86 -item food-frequency questionnaire validated for Portuguese pregnant women. ${ }^{22}$ Through this questionnaire, women were asked once, in the immediate postpartum period, to recall their usual dietary intake during the whole pregnancy. To estimate food consumption, the frequency reported for each food item was multiplied by their predetermined average portion pattern in grams. Food Processor Plus 6.0 (ESHA Research Inc, Salem, OR) was used to convert the consumption of food items into nutrients, based on United States Department of Agriculture food composition data, and was complemented with nutrient composition from the Portuguese Table of Food Composition. ${ }^{23}$ Total macronutrient intakes $(\mathrm{g} / \mathrm{kg} / \mathrm{d}$ of prepregnancy body weight), total energy intake $(\mathrm{kcal} / \mathrm{d})$, and the percentage of total energy value generated from each macronutrient (\%TEV) were analyzed and then compared with the dietary reference intakes (DRIs) from the Food and Nutrition Board, Institute of Medicine. ${ }^{24,25}$

The mother's prepregnancy BMI $\left(\mathrm{kg} / \mathrm{m}^{2}\right)$ was calculated based on the recalled body weight closer to the start of pregnancy and the measured height, using a wall-mounted stadiometer (Seca 240; Seca Medical Scales and Measuring Devices, Hamburg, Germany). Mothers were classified as underweight (BMI < 18.5), normal weight (BMI 18.5-24.9), overweight (BMI 25-29.9), and obese (BMI $\geq 30){ }^{26}$ For calculation of GWG, baseline weight was considered as either the weight measured at the first obstetric visit within the first 10 weeks of gestation (preferentially) or recalled body weight closest to conception.

Neonatal anthropometric measurements were scheduled to be performed within the first 72 hours after birth. Direct measurements were taken for weight, length, and midarm circumference (MAC), using the recommended procedures. ${ }^{16}$ Indices derived from weight and length were calculated to estimate body composition: weight/length index (W/L) as weight $(\mathrm{g}) /$ length $(\mathrm{cm})$, BMI as weight $(\mathrm{kg}) /$ squared length $(\mathrm{m})$, and ponderal index (PI) as weight (g)/cubed length (cm). ${ }^{16}$ WHO Anthro (version 3.2.2, 2011; www.who.int/ childgrowth/software/en/) was used for calculation and analyses calculation of age- and sex-specific z-scores of anthropometric data. ${ }^{27}$

The body composition of the neonates was measured using ADP (Pea Pod; Life Measurement Instruments, Concord, CA), a two-compartment model measuring body mass $(\mathrm{kg})$ with precision of $0.1 \mathrm{~g}$ fat mass (FM) and fat-free mass (FFM). The percentage of FM (\%FM) was calculated from body density assuming the density of fat to be 0.9007 , and age- and genderspecific densities of FFM were computed based on the data of Fomon. ${ }^{19}$ Mass and volume calibrations took the infant's 
Maternal Nutrition and Neonatal Body Composition Pereira-da-Silva et al.

Table 1 Recommended and estimated daily intakes of macronutrient and energy during pregnancy

\begin{tabular}{|c|c|c|c|c|c|}
\hline & \multirow[t]{2}{*}{ Recommended daily intakes } & \multicolumn{4}{|c|}{ Estimated daily intakes } \\
\hline & & Mean & (SD) & DRIs & $\%$ \\
\hline Energy (kcal) & $2,200-2,900^{24}$ & 2,982 & $(702)$ & $\begin{array}{l}< \\
= \\
>\end{array}$ & $\begin{array}{l}12 \\
37 \\
51\end{array}$ \\
\hline \%TEV from protein & $10-35^{25}$ & 18.06 & $(2.58)$ & $=$ & 100 \\
\hline \%TEV from carbohydrates & $45-65^{25}$ & 49.90 & $(5.17)$ & $\begin{array}{l}< \\
=\end{array}$ & $\begin{array}{l}19 \\
81\end{array}$ \\
\hline \%TEV from lipids & $20-35^{25}$ & 33.66 & $(4.03)$ & $\begin{array}{l}= \\
>\end{array}$ & $\begin{array}{l}62 \\
38\end{array}$ \\
\hline Protein $(\mathrm{g} / \mathrm{kg})$ & $1.1^{25}$ & $2.2^{\mathrm{a}}$ & $(1.1 ; 4.5)^{b}$ & $<$ or $=$ & 100 \\
\hline
\end{tabular}

Abbreviations: \%TEV, percentage of total energy value; DRIs, dietary reference intakes.

${ }^{a}$ Median.

${ }^{\mathrm{b}}$ Minimum; maximum.

identification bracelet and the umbilical cord clip into account.

To minimize intra- and interobserver variations, measurements were undertaken by the same trained observers: anthropometry (performed by ARS or CC supervised by LP-S) and ADP (performed by TC or TG supervised by RN).

Data were analyzed using the Statistical Package for the Social Sciences 19.0 for Windows (SPSS Inc., Chicago, IL). Results were expressed as mean (standard deviation [SD]) or median (minimum, maximum), as appropriate. Linear multiple regression analysis was performed including variables identified by univariate analysis $(p<0.15)$; explanatory models for either neonatal anthropometry or ADP measurements were adjusted to prepregnancy BMI, energy and macronutrient intakes during pregnancy, and GWG. The explanatory models used prepregnancy BMI either as a continuous variable or dichotomized as categorical for overweight (threshold $\left.25 \mathrm{~kg} / \mathrm{m}^{2}\right)^{17}$ to differentiate between the influence of the gradual, continuous variation of BMI and the role of overweight/obesity versus non-overweight on neonatal anthropometry or ADP measurements. The level of significance was $\alpha=0.05$.

\section{Results}

A total of 106 mothers were invited and 100 mother-infant pairs were recruited with a mean (SD) gestational age of 39.6 (1.0) weeks. Neonates had birth weight of $3.360(0.359) \mathrm{kg}$ and $55(55 \%)$ of them were female. All neonates were assessed at a median postnatal age of 50 (min. 23; max. 75) hours. No significant demographic differences were found between mother-infant pairs who accepted and rejected to participate (data not shown).

The age of the mothers was 29.7 (6.1) years, and their median prepregnancy BMI was $21.9 \mathrm{~kg} / \mathrm{m}^{2}$ (min. 16.6; max. 37.3 ) with a distribution of $6 \%$ underweight, $76 \%$ normal weight, $12 \%$ overweight, and $6 \%$ obese according to BMI; no significant differences were found between mothers of male and female offspring. The median GWG was $13 \mathrm{~kg}$ (min. 4; max. 42); no significant difference was found between mothers of male and female offspring.

The energy and macronutrient intakes during pregnancy are described and categorized in - Table 1. In 51\% of the mothers, the estimated total energy intake was above the recommendations..$^{24,25}$ The body composition of the neonates, evaluated by anthropometry and by ADP, is described in - Table 2. Male offspring were found to have significantly greater weight $(p=0.022)$, length $(p<0.001)$, and FFM $(p=0.003)$ compared with females. A significant positive correlation was found between anthropometric measurements and ADP measurements (-Table $\mathbf{3}$ ). The associations found by univariate analysis are presented in - Table $\mathbf{4}$. The following associations were found through multivariate analysis:

- Prepregnancy overweight was associated with greater offspring weight, $\mathrm{W} / \mathrm{L}, \mathrm{BMI}$, and FFM in the whole sample (-Table 5). Only in male offspring, prepregnancy overweight was also associated with greater MAC, PI, and FM (-Table 6).

- The \%TEV from carbohydrate adjusted to continuous prepregnancy BMI was positively associated with offspring MAC ( $\beta$-estimate $=0.045 ; 95 \%$ confidence interval $[\mathrm{CI}]$ : $0.010,0.081 ; p=0.012)$ and $\mathrm{W} / \mathrm{L}(\beta$-estimate $=0.215$; $95 \%$ CI: $0.003,0.426 ; p=0.047$ ) in the whole sample.

- The GWG was neither associated with neonatal anthropometric measurements nor with ADP measurements in the whole sample. Only in female offspring, the GWG adjusted to continuous prepregnancy BMI was positively associated with weight, length, and MAC ( - Table 7).

\section{Discussion}

Several factors are known to affect the body composition of the growing fetus, including prepregnancy BMI, diet during pregnancy, GWG, transport systems of the placenta, genetic potential of the fetus, and endocrine status and intermediate metabolism of the mother, placenta, and fetus. ${ }^{1}$ This crosssectional study analyzed the adjusted effect of three major 
Maternal Nutrition and Neonatal Body Composition Pereira-da-Silva et al.

Table 2 Neonatal body composition within the first 72 hours after birth, estimated by anthropometry and measured by air displacement plethysmography

\begin{tabular}{|c|c|c|c|c|c|c|c|}
\hline \multirow{2}{*}{$\begin{array}{l}\text { Measurements with } \\
\text { normal distribution }\end{array}$} & \multirow[t]{2}{*}{ Mean } & \multirow[t]{2}{*}{ (SD) } & \multicolumn{2}{|r|}{ Males } & \multicolumn{2}{|c|}{ Females } & \multirow[t]{2}{*}{$p$} \\
\hline & & & Mean & (SD) & Mean & (SD) & \\
\hline Weight (kg) & 3.360 & (0.359) & 3.450 & $(0.347)$ & 3.286 & $(0.354)$ & 0.022 \\
\hline $\mathrm{W} / \mathrm{L}(\mathrm{g} / \mathrm{cm})$ & 68.35 & (5.79) & 69.28 & $(5.89)$ & 67.59 & (5.65) & 0.147 \\
\hline $\mathrm{PI}\left(\mathrm{g} / \mathrm{cm}^{3}\right)$ & 0.028 & $(0.002)$ & 0.028 & $(0.002)$ & 0.029 & $(0.002)$ & 0.121 \\
\hline$\% \mathrm{FM}$ & 11.37 & $(4.07)$ & 11.11 & $(3.52)$ & 11.59 & $(4.49)$ & 0.556 \\
\hline FM (kg) & 0.369 & $(0.156)$ & 0.368 & $(0.139)$ & 0.370 & $(0.170)$ & 0.945 \\
\hline FFM (kg) & 2.811 & $(0.250)$ & 2.892 & $(0.242)$ & 2.744 & $(0.238)$ & 0.003 \\
\hline \multirow{2}{*}{$\begin{array}{l}\text { Measurements } \\
\text { with non-normal } \\
\text { distribution }\end{array}$} & \multirow[t]{2}{*}{ Median } & \multirow[t]{2}{*}{ (Min; Max) } & \multicolumn{2}{|r|}{ Males } & \multicolumn{2}{|c|}{ Females } & \multirow[t]{2}{*}{$p$} \\
\hline & & & Median & (Min; Max) & Median & (Min; Max) & \\
\hline Length $(\mathrm{cm})$ & 49.25 & $(45.0 ; 53.8)$ & 49.80 & $(45.8 ; 53.5)$ & 48.70 & $(45.0 ; 53.8)$ & $<0.001$ \\
\hline MAC $(\mathrm{cm})$ & 10.80 & $(8.7 ; 13.7)$ & 11.00 & $(8.7 ; 13.7)$ & 10.50 & $(9.0 ; 12.5)$ & 0.307 \\
\hline BMI $\left(\mathrm{kg} / \mathrm{m}^{2}\right)$ & 13.92 & $(11.61 ; 16.87)$ & 13.86 & $(11.99 ; 16.87)$ & 13.94 & $(11.61 ; 15.93)$ & 0.985 \\
\hline
\end{tabular}

Abbreviations: \%FM, percentage of fat mass; BMI, body mass index; FFM, fat-free mass; FM, fat mass; MAC, midarm circumference; PI, ponderal index; $\mathrm{W} / \mathrm{L}$, weight/length index.

Table 3 Correlation between neonatal anthropometric measurements and air displacement plethysmography measurements

\begin{tabular}{|c|c|c|c|c|c|c|}
\hline \multirow[t]{2}{*}{ Measurements } & \multicolumn{2}{|c|}{ \%FM } & \multicolumn{2}{|c|}{ FM (kg) } & \multicolumn{2}{|c|}{ FFM (kg) } \\
\hline & $r$ & $p$ & $r$ & $P$ & $r$ & $p$ \\
\hline W (kg) & 0.566 & $0.000^{\mathrm{a}}$ & 0.699 & $0.000^{\mathrm{a}}$ & 0.872 & $0.000^{\mathrm{a}}$ \\
\hline $\mathrm{L}(\mathrm{cm})$ & 0.342 & $0.001^{\mathrm{a}}$ & 0.463 & $0.000^{\mathrm{a}}$ & 0.718 & $0.000^{\mathrm{a}}$ \\
\hline $\mathrm{MAC}(\mathrm{cm})$ & 0.483 & $0.000^{\mathrm{a}}$ & 0.600 & $0.000^{a}$ & 0.678 & $0.000^{\mathrm{a}}$ \\
\hline $\mathrm{W} / \mathrm{L}(\mathrm{g} / \mathrm{cm})$ & 0.572 & $0.000^{\mathrm{a}}$ & 0.695 & $0.000^{\mathrm{a}}$ & 0.790 & $0.000^{\mathrm{a}}$ \\
\hline BMI $\left(\mathrm{kg} / \mathrm{m}^{2}\right)$ & 0.496 & $0.000^{\mathrm{a}}$ & 0.579 & $0.000^{\mathrm{a}}$ & 0.549 & $0.000^{\mathrm{a}}$ \\
\hline $\mathrm{PI}\left(\mathrm{g} / \mathrm{cm}^{3}\right)$ & 0.312 & $0.002^{\mathrm{a}}$ & 0.330 & $0.001^{\mathrm{a}}$ & 0.173 & 0.085 \\
\hline
\end{tabular}

Abbreviations: \%FM, percentage of fat mass; BMI, body mass index; FFM, fat-free mass; FM, fat mass; L, length; MAC, midarm circumference; PI, ponderal index; $W$, birth weight; $W / L$, birth weight/ length index.

${ }^{a} p<0.050$.

Table 4 Associations found by univariate analysis between prepregnancy BMI, energy and macronutrient intakes during pregnancy, and gestational weight gain and body composition of offspring

\begin{tabular}{|l|l|l|l|l|l|l|l|l|l|}
\hline$p$ Value & Weight & Length & MAC & W/L & BMI & PI & \%FM & FM & FFM \\
\hline BMI (continuous) & $\mathbf{0 . 0 0 7}$ & 0.342 & 0.202 & $\mathbf{0 . 0 0 3}$ & $\mathbf{0 . 0 0 4}$ & $\mathbf{0 . 0 2 6}$ & 0.168 & $\mathbf{0 . 0 5 2}$ & $\mathbf{0 . 0 1 1}$ \\
\hline BMI (categorical) & $\mathbf{0 . 0 1 7}$ & 0.205 & 0.187 & $\mathbf{0 . 0 1 5}$ & $\mathbf{0 . 0 3 4}$ & 0.181 & 0.940 & 0.488 & $\mathbf{0 . 0 0 6}$ \\
\hline GWG & $\mathbf{0 . 1 2 6}$ & $\mathbf{0 . 0 9 1}$ & $\mathbf{0 . 1 4 5}$ & 0.216 & 0.543 & 0.825 & 0.540 & 0.459 & 0.175 \\
\hline Energy (kcal) & 0.602 & 0.382 & 0.488 & 0.765 & 0.947 & 0.648 & 0.295 & 0.423 & 0.807 \\
\hline Protein (g) & 0.481 & 0.392 & 0.619 & 0.569 & 0.793 & 0.887 & 0.727 & 0.968 & 0.338 \\
\hline Carbohydrates (g) & 0.248 & $\mathbf{0 . 1 2 6}$ & 0.198 & 0.400 & 0.800 & 0.651 & 0.168 & 0.227 & 0.404 \\
\hline Lipids (g) & 0.947 & 0.684 & 0.918 & 0.806 & 0.640 & 0.536 & 0.604 & 0.808 & 0.861 \\
\hline \%TEV from protein & $\mathbf{0 . 0 3 8}$ & $\mathbf{0 . 0 0 4}$ & $\mathbf{0 . 0 2 1}$ & $\mathbf{0 . 1 4 3}$ & 0.731 & 0.331 & $\mathbf{0 . 1 3 0}$ & $\mathbf{0 . 1 1 5}$ & $\mathbf{0 . 0 6 8}$ \\
\hline \%TEV from carbohydrates & $\mathbf{0 . 0 2 8}$ & $\mathbf{0 . 0 2 9}$ & $\mathbf{0 . 0 1 2}$ & $\mathbf{0 . 0 5 8}$ & 0.247 & 0.917 & $\mathbf{0 . 0 7 2}$ & $\mathbf{0 . 0 5 9}$ & $\mathbf{0 . 0 8 7}$ \\
\hline \%TEV from lipids & 0.174 & 0.422 & $\mathbf{0 . 1 1 4}$ & 0.169 & 0.234 & 0.459 & 0.215 & 0.179 & 0.371 \\
\hline
\end{tabular}

Abbreviations: \%FM, percentage of fat mass; \%TEV, percentage of total energy value; BMI, body mass index; FFM, fat-free mass; FM, fat mass; GWG, gestational weight gain; MAC, midarm circumference; PI, ponderal index; W/L, weight/length index.

Note: Associations with $p<0.15$ (bold) were considered for linear multiple regression analysis. 
Table 5 Adjusted associations between neonatal measurements and prepregnancy overweight (BMI $\geq 25 \mathrm{~kg} / \mathrm{m}^{2}$ ) in the whole sample

\begin{tabular}{|l|l|l|}
\hline \multirow{2}{*}{ Neonatal measurements } & Prepregnancy BMI & \multirow{2}{*}{$p$ Value } \\
\cline { 2 - 2 } & $\beta$-Estimate $(95 \% \mathrm{Cl})$ & \\
\hline Weight & \\
\hline $\mathrm{W} / \mathrm{L}^{\mathrm{b}}$ & $0.233(0.056,0.410)$ & $<0.05$ \\
\hline $\mathrm{BMI}^{\mathrm{c}}$ & $3.646(0.728,6.563)$ & $<0.05$ \\
\hline $\mathrm{FFM}^{\mathrm{b}}$ & $0.565(0.043,1.088)$ & $<0.05$ \\
\hline
\end{tabular}

Abbreviations: \%TEV, percentage of total energy value; BMI, body mass index; FFM, fat-free mass; W/L, weight/length index.

Notes: Variables considered for the multivariable model: a-prepregnancy BMI, gestational weight gain, \%TEV from protein, and \%TEV from carbohydrate; b-prepregnancy BMI, \%TEV from protein, and \%TEV from carbohydrate; c-prepregnancy BMI.

Table 6 Adjusted associations of neonatal measurements with prepregnancy overweight (BMI $\geq 25 \mathrm{~kg} / \mathrm{m}^{2}$ ) in males

\begin{tabular}{|l|l|c|}
\hline \multirow{2}{*}{$\begin{array}{l}\text { Neonatal } \\
\text { measurements }\end{array}$} & Prepregnancy BMI & \multirow{2}{*}{$p$ Value } \\
\cline { 2 - 2 } & $\beta$-Estimate $(95 \% \mathrm{Cl})$ & \\
\hline Weight $^{\mathrm{a}}$ & $0.403(0.191,0.615)$ & $<0.01$ \\
\hline Length $^{\mathrm{a}}$ & - & \\
\hline $\mathrm{MAC}^{\mathrm{a}}$ & $0.765(0.111,1.419)$ & $<0.05$ \\
\hline $\mathrm{W} / \mathrm{L}^{\mathrm{b}}$ & $6.943(3.362,10.524)$ & $<0.01$ \\
\hline $\mathrm{BMI}^{\mathrm{b}}$ & $1.162(0.490,1.834)$ & $<0.01$ \\
\hline $\mathrm{PI}^{\mathrm{b}}$ & $0.002(0.000,0.003)$ & $<0.05$ \\
\hline $\mathrm{FM}^{\mathrm{c}}$ & $0.120(0.029,0.212)$ & $<0.05$ \\
\hline $\mathrm{FFM}^{\mathrm{d}}$ & $0.266(0.116,0.416)$ & $<0.01$ \\
\hline
\end{tabular}

Abbreviations: \%TEV, percentage of total energy value; BMI, body mass index; FFM, fat-free mass; FM, fat mass; MAC, midarm circumference; PI, ponderal index; $\mathrm{W} / \mathrm{L}$, weight/length index.

Notes: Variables considered for the multivariable model: a-prepregnancy BMI, \%TEV from protein, and \%TEV from carbohydrate; bprepregnancy BMI; c-prepregnancy BMI and \%TEV from carbohydrate; $d$ - prepregnancy BMI and \%TEV from protein.

Table 7 Associations of neonatal measurements in females with gestational weight gain adjusted to continuous prepregnancy BMI

\begin{tabular}{|l|l|c|}
\hline \multirow{2}{*}{$\begin{array}{l}\text { Neonatal } \\
\text { measurements }\end{array}$} & Gestational weight gain & \multirow{2}{*}{$p$ Value } \\
\cline { 2 - 2 } & $\beta$-Estimate $(95 \% \mathrm{Cl})$ & \\
\hline Weight $^{\mathrm{a}}$ & $0.014(0.000,0.028)$ & $<0.05$ \\
\hline Length $^{\mathrm{b}}$ & $0.087(0.016,0.157)$ & $<0.05$ \\
\hline MAC $^{\mathrm{b}}$ & $0.037(0.001,0.073)$ & $<0.05$ \\
\hline
\end{tabular}

Abbreviation: MAC, midarm circumference.

Notes: Variables considered for the multivariable model: a-gestational weight gain and \%TEV from carbohydrate; b-gestational weight gain, \%TEV from carbohydrate, and \%TEV from protein. maternal nutrition factors (prepregnancy BMI, energy and macronutrient intakes during the pregnancy, and GWG) on the body composition of neonates born to mothers without other apparent factors affecting the intrauterine growth. To the best of our knowledge, the adjusted effect of these three maternal nutrition factors on the body composition of healthy full-term infants assessed by an accurate direct method (ADP) has not yet been published.

The use of the ADP, a reliable and validated method for measuring the body composition of the neonates, is a strength of this study. ${ }^{19,28}$ Neonatal body composition was assessed within the first 72 hours after birth. This schedule allows the best feasible estimate of the intrauterine nutritional status ${ }^{8}$ while minimizing the effect of postnatal factors, including the feeding regimen. Nevertheless, due to safety concerns, it was not feasible to perform the assessments in the first hours after birth; thus, the physiological water loss occurring in the first days after birth is an uncontrollable bias.

Other limitations have to be acknowledged. A systematically recruited convenience sample was studied. Despite its convenience size, the associations obtained in this sample are strong, as evidenced by high statistical significance and narrow CIs. The food frequency questionnaire has been validated in pregnancy, is considered suitable for ranking individuals based on dietary intake, and is feasible for surveying large samples. ${ }^{10}$ On the other hand, it may have limited accuracy in quantifying energy intake and absolute intakes of macronutrients. ${ }^{29}$ Prepregnancy BMI may have been biased by inaccurate self-reported body weight; however, reasonable agreements have been described between self-reported weight and either the weight recorded in medical files or the weight measured at the first prenatal visit. ${ }^{30}$ Some of the factors affecting the nutritional status of the fetus, such as placenta characteristics, were not feasible to obtain. To control the potential impact of placental pathology on outcome measurements, neonates born to mothers with adverse conditions known to affect fetal nutrition and growth were excluded. Moreover, only assumed healthy full-term AGA neonates were included.

\section{Effect of Prepregnancy BMI on Offspring Body Composition}

The present study showed that prepregnancy overweight $\left(B M I \geq 25 \mathrm{~kg} / \mathrm{m}^{2}\right)$ was associated with greater offspring weight, W/L, and FFM. Prepregnancy weight has been reported to have the strongest correlation with birth weight, ${ }^{4}$ and evidence indicates that prepregnancy overweight and obesity are positively associated with increased offspring body size at birth. ${ }^{3,4,9,10,13}$ While the positive association between prepregnancy BMI and offspring body size is consensual, the variation of neonatal body composition, that is, proportions of FM and FFM, responsible for the increase in weight remains controversial. Eriksson et $\mathrm{al}^{31}$ found no correlation between prepregnancy BMI and neonatal \%FM measured by ADP. Forsum et $\mathrm{al}^{2}$ interpreted the correlation between birth weight and prepregnancy total body fat as a consequence of general augmentation of fetal growth rather than a specific stimulation of adipose tissue growth. On the 
other hand, greater FM and/or greater \%FM measured by ADP have been reported in infants born to overweight/obese mothers. ${ }^{17,18}$ In this study, associations between prepregnancy overweight and greater adiposity parameters (PI and FM) were found only in males. This association is especially relevant because it has been reported that males have significantly less FM and \%FM at birth than females. ${ }^{28,31}$ Gender dimorphism response to maternal nutrition status was found in rats after intrauterine exposure to a high-saturated-fat diet, which resulted in compromise of $\beta$-cell development and function and programming of male offspring to be heavier, hyperleptinemic, and hyperinsulinemic. ${ }^{32}$

\section{Effect of Energy and Macronutrient Intakes during Pregnancy on Offspring Body Composition}

We hypothesized that energy and macronutrient intakes during pregnancy might have a measurable effect on the body composition of offspring. No association was found between absolute maternal intakes of energy and macronutrients and body composition of the neonates. Only a positive association between the percentage of energy from carbohydrate and neonatal adiposity, estimated by MAC and $\mathrm{W} / \mathrm{L}$, was found, in accordance with published data. ${ }^{9}$ No consistent data have been reported regarding the effect of diet during pregnancy on offspring body composition. Among well-nourished women, 7.2 to $12.7 \%$ of the variability in offspring birth weight may be explained by macronutrient intake (especially protein) adjusted for energy intake, prepregnancy BMI, and offspring gender. ${ }^{12}$ Maternal weight gain has been found to be significantly associated with both total energy intake and energy intake from protein, lipid of animal origin, and carbohydrate during the second trimester of pregnancy. ${ }^{9}$ However, these referred associations were not reflected in the birth-size parameters in the offspring. ${ }^{9}$ It is possible that, in the absence of specific micronutrient deficiencies, the effects of maternal diet on fetal growth occur only when women have low prepregnancy BMI or when their energy needs during pregnancy are not met. ${ }^{9}$ In addition, although balanced increased energy and protein supplementation may improve fetal growth, highprotein or balanced-protein supplementation alone is not beneficial and may even be harmful to the fetus. ${ }^{5}$ In this study, reported energy and protein intakes during pregnancy were greater than recommended and just $6 \%$ of the mothers were underweight, which may explain the absence of associations between the absolute energy and macronutrient intakes during pregnancy and neonatal body composition. From the present data, it may be speculated that the intermediate metabolism of normal weight women protects the fetus against excessive energy and macronutrient intakes, while dysregulated intermediate metabolism in overweight and obese women may independently affect the nutritional status of the offspring.

\section{Effect of Gestational Weight Gain on Offspring Body Composition}

The hypothesized measurable effect of GWG on the body composition of the offspring was not found in the whole sample. Only in females, a positive association was found between the GWG and offspring body size (weight, length, and MAC), adjusted to prepregnancy BMI. The median of GWG in the present sample was $13 \mathrm{~kg}$. It has been reported that excessive GWG is associated with increased body weight and body fat at birth. ${ }^{7}$ Although excessive GWG is not necessarily due to increased FM, it is eventually associated with more body fat in the offspring. Differential effects regarding the type of weight gained during gestation remains unclear. Butte et al found birth weight to be positively correlated with mother's gain in total body water and FFM but not FM; thus, it was speculated that the positive association between offspring birth weight and maternal FFM was mediated by plasma volume expansion. ${ }^{6}$

\section{Summary and Conclusion}

This cross-sectional study analyzed the adjusted effect of three major maternal nutrition factors potentially affecting the fetal body composition, as assessed early after birth. A reliable direct method for body composition assessment was used, and only healthy full-term AGA neonates were included. An association between prepregnancy BMI and greater offspring weight, W/L, and FFM was found. In males, greater adiposity was associated with prepregnancy BMI, while in females greater body size at birth was associated with GWG. Higher energy intake from carbohydrate was positively associated with offspring MAC and $\mathrm{W} / \mathrm{L}$. These results need to be confirmed either by larger observational studies or interventional studies controlled for additional factors affecting fetal nutrition, using accurate estimates of both maternal diet and neonatal body composition.

\section{Funding}

This project was partially sponsored by the Portuguese Neonatal Society through the "Milupa 2010" grant for infant nutrition research.

\section{Acknowledgments}

The authors are grateful to Ana Luisa Papoila, MSc, PhD, and Marta Alves, MSc, Research Unit of Centro Hospitalar de Lisboa Central, Lisbon, for their contribution to the statistical analysis; Laura Pereira, RD, Lisbon School od Health Technology, for the contribution in the methodology for assessment of maternal diet; Kayla Bridges, MS, RD, CSP, CNSC, St. John Providence Children's Hospital, Detroit, and Lino Mendes, RD, MSc, Lisbon School od Health Technology, for the critical review of the manuscript.

\section{Conflict of Interest}

There is no conflict of interest to declare. 


\section{References}

1 Cetin I, Cardellicchio M. Physiology of pregnancy: interaction between mother and child. Ann Nestlé [Eng] 2010;68:7-15

2 Forsum E, Löf M, Olausson H, Olhager E. Maternal body composition in relation to infant birth weight and subcutaneous adipose tissue. Br J Nutr 2006;96(2):408-414

3 Jolly MC, Sebire NJ, Harris JP, Regan L, Robinson S. Risk factors for macrosomia and its clinical consequences: a study of 350,311 pregnancies. Eur J Obstet Gynecol Reprod Biol 2003;111(1):9-14

4 Mehta SH. Nutrition and pregnancy. Clin Obstet Gynecol 2008; 51(2):409-418

5 Ota E, Tobe-Gai R, Mori R, Farrar D. Antenatal dietary advice and supplementation to increase energy and protein intake. Cochrane Database Syst Rev 2012;9:CD000032

6 Butte NF, Ellis KJ, Wong WW, Hopkinson JM, Smith EO. Composition of gestational weight gain impacts maternal fat retention and infant birth weight. Am J Obstet Gynecol 2003;189(5):1423-1432

7 Hull HR, Thornton JC, Ji Y, et al. Higher infant body fat with excessive gestational weight gain in overweight women. Am J Obstet Gynecol 2011;205(3):e1-e7

8 Catalano PM, Thomas AJ, Avallone DA, Amini SB. Anthropometric estimation of neonatal body composition. Am J Obstet Gynecol 1995;173(4):1176-1181

9 Lagiou P, Tamimi RM, Mucci LA, Adami H-O, Hsieh C-C, Trichopoulos D. Diet during pregnancy in relation to maternal weight gain and birth size. Eur J Clin Nutr 2004;58(2):231-237

10 Moore VM, Davies MJ, Willson KJ, Worsley A, Robinson JS. Dietary composition of pregnant women is related to size of the baby at birth. J Nutr 2004;134(7):1820-1826

11 Cucó G, Arija V, Iranzo R, Vilà J, Prieto MT, Fernández-Ballart J. Association of maternal protein intake before conception and throughout pregnancy with birth weight. Acta Obstet Gynecol Scand 2006;85(4):413-421

12 Briese V, Voigt M, Hermanussen M, Wittwer-Backofen U. Morbid obesity: pregnancy risks, birth risks and status of the newborn. Homo 2010;61(1):64-72

13 Black MH, Sacks DA, Xiang AH, Lawrence JM. The relative contribution of prepregnancy overweight and obesity, gestational weight gain, and IADPSG-defined gestational diabetes mellitus to fetal overgrowth. Diabetes Care 2013;36(1):56-62

14 Olhager E, Forsum E. Assessment of total body fat using the skinfold technique in full-term and preterm infants. Acta Paediatr 2006;95(1):21-28

15 Schmelzle HR, Quang DN, Fusch G, Fusch C. Birth weight categorization according to gestational age does not reflect percentage body fat in term and preterm newborns. Eur J Pediatr 2007;166(2): 161-167

16 Pereira-da-Silva L. Neonatal anthropometry: a tool to evaluate the nutritional status, and to predict early and late risks. In: Preedy VR, ed. The Handbook of Anthropometry: Physical Measures of Human Form in Health and Disease. New York: Springer; 2012: 1079-1104
17 Hull HR, Dinger MK, Knehans AW, Thompson DM, Fields DA. Impact of maternal body mass index on neonate birthweight and body composition. Am J Obstet Gynecol 2008;198(4):e1-e6

18 Andres A, Shankar K, Badger TM. Body fat mass of exclusively breastfed infants born to overweight mothers. J Acad Nutr Diet 2012;112(7):991-995

19 Ellis KJ, Yao M, Shypailo RJ, Urlando A, Wong WW, Heird WC. Bodycomposition assessment in infancy: air-displacement plethysmography compared with a reference 4-compartment model. Am J Clin Nutr 2007;85(1):90-95

20 Olsen IE, Groveman SA, Lawson ML, Clark RH, Zemel BS. New intrauterine growth curves based on United States data. Pediatrics 2010;125(2):e214-e224

21 Wong S, Ordean A, Kahan M; Maternal Fetal Medicine Committee; Family Physicians Advisory Committee; Medico-Legal Committee; Society of Obstetricians and Gynaecologists of Canada. Substance use in pregnancy. J Obstet Gynaecol Can 2011;33(4):367-384

22 Pinto E, Severo M, Correia S, dos Santos Silva I, Lopes C, Barros H. Validity and reproducibility of a semi-quantitative food frequency questionnaire for use among Portuguese pregnant women. Matern Child Nutr 2010;6(2):105-119

23 Oliveira L, Porto A. Food Composition Table. Lisbon: Instituto Nacional de Saúde Dr. Ricardo Jorge; 2007

24 Kaiser L, Allen LH; American Dietetic Association. Position of the American Dietetic Association: nutrition and lifestyle for a healthy pregnancy outcome. J Am Diet Assoc 2008;108(3):553-561

25 Institute of Medicine, Food and Nutrition Board. Dietary Reference Intakes for Energy, Carbohydrate, Fiber, Fat, Fatty Acids, Cholesterol, Protein, and Amino Acids (Macronutrients). Washington, DC: National Academy Press; 2010

26 WHO Consultation. Obesity: Preventing and Managing the Global Epidemic. GenevaWHO Technical Report Series 8942000

27 WHO Multicentre Growth Reference Study Group. WHO Child Growth Standards based on length/height, weight and age. Acta Paediatr 2006 Suppl 450:76-85

28 Hawkes CP, Hourihane JO, Kenny LC, Irvine AD, Kiely M, Murray DM. Gender- and gestational age-specific body fat percentage at birth. Pediatrics 2011;128(3):e645-e651

29 Subar AF, Kipnis V, Troiano RP, et al. Using intake biomarkers to evaluate the extent of dietary misreporting in a large sample of adults: the OPEN study. Am J Epidemiol 2003;158(1):1-13

30 Holland E, Moore Simas TA, Doyle Curiale DK, Liao X, Waring ME. Self-reported pre-pregnancy weight versus weight measured at first prenatal visit: effects on categorization of pre-pregnancy body mass index. Matern Child Health J 2012;17(10):1872-1878

31 Eriksson B, Löf M, Forsum E. Body composition in full-term healthy infants measured with air displacement plethysmography at 1 and 12 weeks of age. Acta Paediatr 2010;99(4):563-568

32 Cerf ME, Chapman CS, Louw J. High-fat programming of hyperglycemia, hyperinsulinemia, insulin resistance, hyperleptinemia, and altered islet architecture in 3-month-old Wistar rats. ISRN Endocrinol 2012;2012:627270 